1 Universidade Estadual de Campinas (Unicamp) Piracicaba (SP), Brasil. aglopes72@gmail.com

2 Universidade Estadual de Campinas (Unicamp) Piracicaba (SP), Brasil. apereira@fop.unicamp.br

3 Universidade Estadual de Campinas (Unicamp) Piracicaba (SP), Brasil. emiliopraddo@ig.com.br

4 Universidade Estadual de Campinas (Unicamp) Piracicaba (SP), Brasil. mialhe@fop.unicamp.br

\section{Irregularidades sanitárias na promoção comercial em rótulos de produtos para lactentes e os riscos para a saúde}

\author{
Sanitary irregularities in the commercial promotion and labeling of \\ products for nurslings and risks to health
}

Alexandre Gomes Lopes ${ }^{\mathbf{1}}$, Antônio Carlos Pereira ${ }^{2}$, Emílio Prado da Fonseca $\mathbf{3}$, Fábio Luiz Mialhe $\mathbf{4}^{\mathbf{4}}$

RESUMO Regulamentações sanitárias para crianças e lactentes buscam controlar estratégias mercadológicas que estimulam o consumo de certos produtos. Na investigação realizada em pontos de venda, verificou-se heterogeneidade na frequência de falhas na rotulagem de bicos, chupetas e mamadeiras em várias marcas. Deficiências nas informações sobre o controle de fabricação e os aspectos de proteção ao aleitamento natural indicam uma conduta intencional das marcas líderes para a manutenção dessa situação, que pode ser agravada pela falta de monitoramento periódico da rotulagem e promoção comercial pela vigilância sanitária, implicando risco de desmame precoce e outros problemas de saúde durante a primeira infância.

PALAVRAS-CHAVE Controle de qualidade. Chupetas. Mamadeiras. Rotulagem de produtos. Vigilância sanitária.

ABSTRACT Sanitary regulations for infants and nurslings seek to control marketing strategies that stimulate the consumption of certain products. In the investigation carried out at points of sale, we verified heterogeneity in the frequency of failures in the labeling of nozzles, pacifiers and nursing bottles in several brands. Deficiency in information on manufacturing control and aspects of breastfeeding protection indicates intentional conduct of the leading brands for the maintenance of such situation, which may be aggravated by the lack of periodic monitoring of the labeling and commercial promotion by health surveillance, implying risk of early weaning and other health problems during early childhood.

KEYWORDS Quality control. Pacifiers. Nursing bottles. Product labeling. Health surveillance. 


\section{Introdução}

Evidências científicas apontam que o aleitamento materno é a fonte de nutrição ideal para o bebê até os 2 anos de idade (WHO, 2007; SALIBA ET AL., 2008; ALBUQUeRQUe ET AL., 2010). O desmame precoce sofre influência das práticas e estratégias mercadológicas de estímulo ao consumo de produtos industrializados, acarretando aumento de Doenças Crônicas Não Transmissiveis (DCNT) e seus fatores de risco (BURLANDY ET AL., 2016). Entre eles, está a inclusão de hábitos bucais deletérios como a sucção de chupeta, que originam problemas para o desenvolvimento maxilofacial (GIMENEZ ET AL., 2008).

Inconformidades nas rotulagens de bicos artificiais e mamadeiras são obstáculos para escolha mais consciente do consumidor. Isso decorre do conflito natural entre interesses privados por aumento contínuo do lucro e ações governamentais para proteção e promoção à saúde (BURLANDY ET AL., 2016). O controle desses riscos é feito pela aplicação de códigos internacionais e normas para vigilância tanto dos alimentos artificiais quanto de bicos, mamadeiras e chupetas que concorrem diretamente com o aleitamento materno exclusivo (MONTEIRO, 2006).

A Norma Brasileira para Comercialização de Alimentos para Lactentes e Crianças de Primeira Infância, Bicos, Chupetas e Mamadeiras (NBCAL) (ANVISA, 2002A, 2002B, 2002C; PAULA; CHAGAS; RAMOS, 2010) se constitui em um diferencial na América Latina e Caribe. Apenas outros seis países (Costa Rica, Guatemala, Panamá, Peru, República Dominicana e Venezuela) têm legislação similar contemplando integralmente o controle na comercialização de substitutos do leite materno e bicos artificiais. No restante, o controle permaneceu voluntário (Chile, Equador) ou parcial (Argentina, Colômbia, Cuba, México, Paraguai) sobre aspectos pontuais do código internacional relacionado com o assunto, mas sem gerar regulamentação própria (WHO, 2007; MONTEIRO, 2006; BURLANDY ET AL., 2016).

A atualização da NBCAL, por meio de resoluções da Agência Nacional de Vigilância Sanitária (Anvisa) em 2001/2002, melhorou a clareza e interpretação do texto original dificultando a impunidade por parte da indústria (MONTEIRO, 2006). O acréscimo da obrigatoriedade de mensagens de advertência tanto na rotulagem quanto na promoção comercial, e da competência para fiscalizar e penalizar infratores, busca o cumprimento dessa legislação (MONTEIRO, 2006; ANVISA, 2002B).

Albuquerque et al. (2010), contudo, verificaram resistência da indústria na adoção das alterações estabelecidas pela norma para comercialização e propaganda de produtos adversários à amamentação. Desse modo, torna-se necessária a investigação da rotulagem e da promoção comercial dos produtos inseridos na NBCAL pela utilização expressiva desses artefatos pela população menor de 1 ano de idade, principalmente nas últimas décadas (ALBUQUeRQUe ET AL., 2010).

Ainda não está suficientemente claro se as rotulagens dos produtos comercializados sob o escopo da NBCAL possuem informações adequadas para os consumidores.

Nas drogarias e supermercados de diferentes municípios, verificaram-se percentuais significativos desses problemas, pois fabricantes e profissionais responsáveis por esses locais favorecem o consumo inconsciente, sustentado com informações tendenciosas e fomentado pela existência de bonificação sobre resultados nas vendas (PAULA; CHAGAS; RAMOS, 2010; SILVA; VIEIRA, 2004).

Dessa forma, o presente estudo teve como objetivo investigar os padrões de rotulagem e a promoção comercial das marcas de mamadeiras, bicos e chupetas expostas à venda em supermercados e drogarias em um município de médio porte no interior do estado de São Paulo.

\section{Material e métodos}

Trata-se de estudo exploratório-descritivo de produtos para lactentes sujeitos a controle 
sanitário, envolvendo dois grupos distintos de estabelecimentos comerciais distribuídos pela cidade de Piracicaba (SP). Esse cenário se justifica dada a influência exercida pelo município e seu setor de serviços na economia e potencial de consumo regional, o alto Índice de Desenvolvimento Humano Municipal (IDHM) (0,785) e a participação no grupo de municípios com nível elevado de riqueza e bons indicadores sociais (SEADE, 2015).

O plano amostral inicial considerou a situação de maior probabilidade de erro $(\mathrm{p}=0,50)$ e intervalo de confiança de $+/-$ $5 \%$, estimando-se a participação de 71 supermercados e 112 drogarias. Contudo, inconsistências durante cruzamento entre bases de dados do Sistema Informatizado da Vigilância Sanitária municipal (Sivisa) e do Cadastro Nacional de Pessoas Jurídicas (CNPJ) acarretaram exclusão prévia de 16 supermercados e 36 drogarias antes mesmo da coleta dos dados.

Desse modo, todos os estabelecimentos com cadastro correto, ativo e endereços atualizados pelos órgãos oficiais tornaram-se elegíveis, além do acréscimo de critério de reposição para participação. Caso fosse verificado no local o enceramento das atividades ou mudança de endereço, outra drogaria ou supermercado em um raio de 200 metros de distância em todas as direções seria abordado para inclusão neste estudo.

Um formulário baseado em modelos da International Baby Food Action (IBFAN BRASIL, 2007) ou Rede Internacional de Proteção pelo Direito de Amamentar - e inspirado na Resolução de Diretoria Colegiada (RDC) Anvisa $n^{0}$ 221/02 (figura 1) - foi utilizado para análise dos produtos estudados durante o mês de agosto de 2012. Esse instrumento abrange quatro dimensões: caracterização do estabelecimento (itens 1 a 4); informações sobre o rótulo, uso correto e seguro do produto comercializado (itens 5 a 19); informações sobre as estratégias para promoção comercial nos locais de venda (itens 20 a 23) e identificação das marcas comerciais disponíveis (item 24).

Para mensuração do volume aceitável de desvios de qualidade por lote, adotou-se o previsto no item 4.5 da $\mathrm{RDC} \mathrm{n}^{0} 221 / 02$; e, para tabulação dos dados e cálculo das frequências, utilizou-se o programa Microsoft Excel $^{\circledR}$ (Versão 2010). 
Figura 1. Formulário para coleta de dados nos estabelecimentos comerciais

\section{FORMULÁRIO PARA COLETA DE DADOS SOBRE COMERCIALIZAÇÃO DE BICOS, MAMADEIRAS E CHUPETAS}

\section{CARACTERÍSTICAS DO ESTABELECIMENTO}

1. TIPO (Drogaria - 1 / Supermercado - 2):

2. ORGANIZAÇÃO (Rede ou Franquia - 1 / Individual - 2):

3. REGIÃO ONDE ESTÁ LOCALIZADO (Centro -1 / Norte - 2/ Sul - 3/ Leste - 4/ Oeste -5):

4. PRODUTOS INFANTIS COMERCIALIZADOS: Bicos - B / Mamadeiras $-\mathrm{M}$ / Chupetas $-\mathrm{C}$

CÓDIGOS DE PREENCHIMENTO: 0 - NÃO COMERCIALIZA / 1 - SIM / 2 - NÃO

INFORMAÇÕES SOBRE O(S) RÓTULO(S) DO(S) PRODUTO(S) COMERCIALIZADO(S)

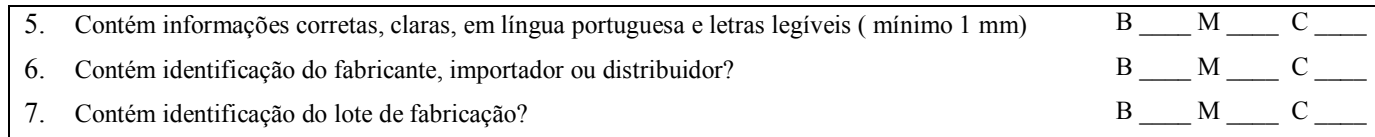

Contém informações quanto ao uso CORRETO e SEGURO em relação a:

8. Colocação do produto em água fervente por 5 minutos antes do uso?

9. Proibição de laços e fitas para fixação ao pescoço prevenindo acidentes (estrangulamento)?

10. Advertência para verificação de danos ( rasgo, perfuração) no produto antes de cada uso?

11. Proibição quanto à alterações nos produtos ( furos maiores nos bicos) prevenindo asfixia?

12. Proibição de imersão (bicos, chupetas) em substâncias doces para prevenção de cáries?

13. Advertência para o uso do produto (mamadeira) somente sob supervisão constante de adulto?

14. Orientações para guarda da embalagem e / ou rótulo do produto para eventuais consultas?

15. Contém frases de advertência preconizadas pelo Ministério da Saúde no(s) painel(is) do produto?

16. Contém frase de advertência em moldura legível, fácil visualização, cores contrastantes e com caracteres idênticos à designação de venda do produto?

17. Contém rótulo isento de fotos, imagens de crianças ou ilustrações humanizadas?

18. Contém rótulo isento de frases ou expressões que sugiram benefícios iguais ou superiores a amamentação ou ser o produto apropriado ao uso infantil?

19. Contém rótulo com informações que possam induzir falso conceito de vantagem ou segurança?

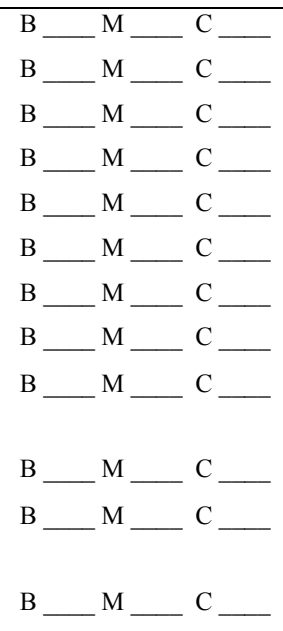

INFORMAÇÕES SOBRE PROMOÇÃO COMERCIAL NO ESTABELECIMENTO ( 1 - SIM / 2 - NÃO)

20. Existem exposições especiais na comercialização dos produtos?
21. Existem cupons de desconto ou preço reduzido (oferta) para comercialização dos produtos?
22. Existem prêmios ou brindes para comercialização dos produtos?
23. Existem apresentações especiais para comercialização dos produtos?

24. MARCAS COMERCIALIZADAS NO ESTABELECIMENTO

BICOS:

CHUPETAS:

MAMADEIRAS:

Fonte: Elaboração própria. 
Um único avaliador, capacitado em monitoramentos da NBCAL, coletou os dados após estudo piloto com 10 estabelecimentos para testar e corrigir possíveis falhas. Durante essa etapa preparatória, identificou-se necessidade de reprodução no restante da ficha dos mesmos campos para preenchimento adotados no item quatro (figura 1). A adequação permitiu maior rapidez e ritmo no registro de cada exemplar avaliado, diferindo um pouco nos itens 9, 11 e 13 por não se aplicarem a todos os produtos.

O critério de escolha entre marcas em cada local considerou se havia: uma mesma marca para os três produtos; a existência de uma marca 'nova' ou 'ainda não avaliada' entre eles; a alternância para prevenção de repetição e concentração em determinada marca e o tipo de embalagem do produto.

O estudo foi submetido ao Comitê de
Ética em Pesquisa (CEP) da Faculdade de Odontologia de Piracicaba (FOP/Unicamp) e dispensado por não envolver diretamente pesquisa com seres humanos conforme Ofício CEP/FOP n 006 /2011, bem como não recebeu suporte financeiro de agências de fomento à pesquisa, de órgãos governamentais ou de instituições privadas relacionadas com o objeto de pesquisa.

\section{Resultados}

A distribuição de supermercados e drogarias que fizeram parte do estudo é apresentada na figura 2. A amostra final contou com 166 estabelecimentos participantes ocorrendo perdas em $7,1 \%$ das drogarias e em $12,6 \%$ dos supermercados estimados na amostra.

Figura 2. Distribuição espacial dos participantes por tipo de estabelecimento e região
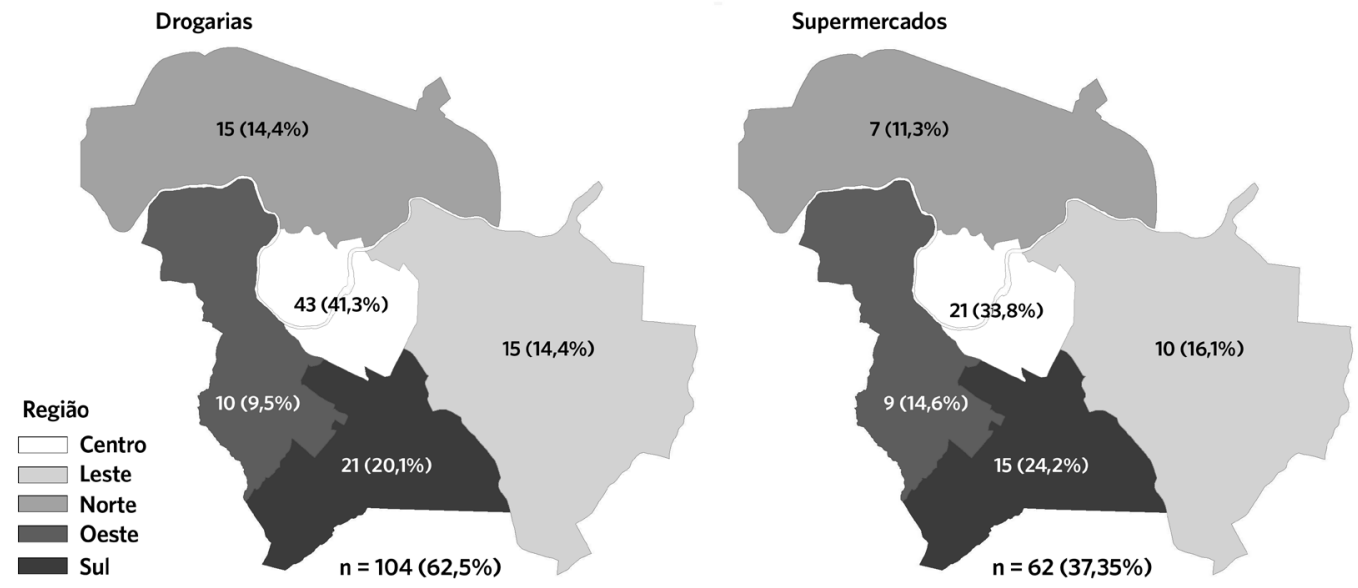

Fonte: Elaboração própria.

A região central do município concentrou o maior número de estabelecimentos em geral, situação oposta ao encontrado na região oeste. Sobre a forma de organização, ocorreu certo equilíbrio na distribuição entre as 62 drogarias de propriedade individual e outras 42 ligadas a redes ou franquias, principalmente na região oeste. Essa situação se inverteu em relação aos supermercados nos quais predominaram redes ou franquias (54,8\%) em relação aos estabelecimentos de propriedade individual (45,2\%). 
Os produtos infantis avaliados foram encontrados com maior frequência em drogarias, apresentando percentuais crescentes, respectivamente, para bicos $(81,7 \%)$, mamadeiras $(83,7 \%)$ e chupetas $(85,6 \%)$. Nos supermercados, a oferta desses mesmos produtos foi bem menor (bicos $-46,8 \%$, mamadeiras $-53,2 \%$ e chupetas $-61,3 \%$ ), sendo a chupeta o produto mais comercializado.

Na tabela 1, estão discriminadas as irregularidades presentes na rotulagem dos produtos.

Tabela 1. Frequência de irregularidades na rotulagem, segundo RDC no 221/02. Piracicaba, SP, 2012

\begin{tabular}{|c|c|c|c|c|c|c|}
\hline \multirow[b]{2}{*}{ Requisitos sanitários - Rótulos } & \multicolumn{3}{|c|}{ Drogarias n (\%) } & \multicolumn{3}{|c|}{ Supermercados n (\%) } \\
\hline & Bico $(n=85)$ & $\begin{array}{r}\text { Mamadeira } \\
\qquad(n=87)\end{array}$ & $\begin{array}{r}\text { Chupeta } \\
(n=89)\end{array}$ & Bico $(n=28)$ & $\begin{array}{r}\text { Mamadeira } \\
(n=34)\end{array}$ & $\begin{array}{r}\text { Chupeta } \\
(n=38)\end{array}$ \\
\hline $\begin{array}{l}\text { *Informações corretas, claras, em língua portuguesa e } \\
\text { letras legíveis. }\end{array}$ & $9(10,6)$ & $2(2,3)$ & $9(10,1)$ & $6(21,4)$ & $5(14,7)$ & $7(18,4)$ \\
\hline *Identificação do fabricante, importador ou distribuidor. & $1(1,2)$ & $1(1,2)$ & $3(3,4)$ & $1(3,6)$ & $1(2,9)$ & $2(5,3)$ \\
\hline `Identificação do lote de fabricação. & $1(1,2)$ & $5(5,7)$ & $4(4,5)$ & $1(3,6)$ & $4(11,8)$ & $4(10,5)$ \\
\hline $\begin{array}{l}\text { *Colocação do produto em água fervente por } 5 \text { min. } \\
\text { antes de cada uso. }\end{array}$ & $6(7,0)$ & $2(2,3)$ & $5(5,6)$ & $3(10,7)$ & $1(2,9)$ & $3(7,9)$ \\
\hline $\begin{array}{l}\text { *Proibição de laços e fitas para prevenção de acidentes } \\
\text { (estrangula mento). }\end{array}$ & * & * & $4(4,5)$ & * & * & $3(7,9)$ \\
\hline $\begin{array}{l}\text { *Advertência para verificação de danos (rasgo, perfura- } \\
\text { ção) a cada uso. }\end{array}$ & $4(4,7)$ & $1(1,2)$ & $5(5,6)$ & $2(7,1)$ & $1(2,9)$ & $2(5,3)$ \\
\hline $\begin{array}{l}\text { ×Proibição quanto a alterações nos produtos prevenindo } \\
\text { asfixia. }\end{array}$ & $5(5,9)$ & $2(2,3)$ & * & $3(10,7)$ & $4(11,8)$ & * \\
\hline $\begin{array}{l}\text { *Proibição de imersão em substâncias doces para } \\
\text { prevenção de cáries }\end{array}$ & $9(10,6)$ & $2(2,3)$ & $4(4,5)$ & $3(10,7)$ & $4(11,8)$ & $2(5,3)$ \\
\hline $\begin{array}{l}\text { *Advertência para uso do produto somente sob super- } \\
\text { visão constante de adulto. }\end{array}$ & $7(8,2)$ & $1(1,2)$ & * & $2(7,1)$ & $2(5,9)$ & * \\
\hline $\begin{array}{l}\text { *Orientação para guarda da embalagem e / ou rótulo } \\
\text { para eventuais consultas. }\end{array}$ & $6(7,0)$ & $2(2,3)$ & $5(5,6)$ & $2(7,1)$ & $4(11,8)$ & $3(7,9)$ \\
\hline $\begin{array}{l}\text { *Frases de advertência preconizadas pelo Ministério da } \\
\text { Saúde no(s) painel(is). }\end{array}$ & $79(93,0)$ & $83(95,4)$ & $82(92,1)$ & $26(92,9)$ & $31(97,1)$ & $34(89,5)$ \\
\hline $\begin{array}{l}\text { *Advertência em moldura legível, fácil visualização, } \\
\text { cores contrastantes e em caracteres idênticos à desig- } \\
\text { nação de venda. }\end{array}$ & $5(5,9)$ & $5(5,7)$ & $8(9,0)$ & $4(14,3)$ & $7(20,6)$ & $6(15,8)$ \\
\hline $\begin{array}{l}\text { *Rótulo isento de fotos, imagens de crianças ou ilustra- } \\
\text { ções humanizadas. }\end{array}$ & $9(10,6)$ & $11(12,6)$ & $16(18,0)$ & $7(25,0)$ & $5(14,7)$ & $11(28,9)$ \\
\hline $\begin{array}{l}\text { *Rótulo isento de frases ou expressões que sugiram } \\
\text { benefícios iguais ou superiores à amamentação ou ser } \\
\text { o produto apropriado ao uso infantil. }\end{array}$ & $38(44,7)$ & $30(34,5)$ & $76(85,4)$ & $14(50,0)$ & $9(26,5)$ & $30(79,0)$ \\
\hline $\begin{array}{l}\text { *Rótulo com informações que possam induzir falso } \\
\text { conceito de vantagem ou segurança. }\end{array}$ & $42(49,4)$ & $52(59,8)$ & $45(50,6)$ & $14(50,0)$ & $19(55,9)$ & $23(60,5)$ \\
\hline
\end{tabular}

Fonte: Elaboração própria. 
Esses resultados mostram discrepância importante entre o maior volume de produtos comercializados por drogarias e a maior quantidade de irregularidades verificadas nos supermercados; assim como desperta maior atenção na distribuição dos problemas em cada produto e marca comercializada, além de distinção entre informações sobre fabricação em si daquelas envolvendo a publicidade feita diretamente nos rótulos.

Nos supermercados, constatou-se menor clareza, informações obrigatórias incompletas ou pouco legíveis e falhas na instrução para higienização prévia de bicos e chupetas em relação às mamadeiras, exceto para identificação do lote de fabricação. Nesses locais, as proibições e advertências nos rótulos para prevenção de acidentes e problemas de saúde também apresentaram percentuais muito superiores nas mamadeiras e bicos. Outro item que apresentou diferenças apenas nas mamadeiras foi orientação para guarda de embalagem.

Nas drogarias, uma frequência menor de irregularidades sobre instruções de uso inseridas na rotulagem pode ter associação com o maior controle sanitário realizado por diferentes órgãos oficiais de fiscalização sobre esses estabelecimentos e fabricantes.

Outros achados relevantes dizem respeito aos mecanismos para monitoramento e controle da propaganda e marketing nos rótulos. Cerca de metade dos bicos e mamadeiras desrespeitaram restrições no layout, proibições no uso de imagens e textos tendenciosos nos rótulos, situação agravada nos resultados encontrados para chupetas. A questão mais crítica envolveu omissões na reprodução das frases preconizadas pelo Ministério da Saúde que advertem sobre prejuízos à fala e à dentição da criança por uso prolongado de bicos, mamadeiras e chupetas.

As irregularidades nas estratégias promocionais adotadas por drogarias e supermercados para potencializar a venda dos produtos são apresentadas na tabela 2 .

Havia publicidade ostensiva em

Tabela 2. Violações na promoção comercial por estabelecimento conforme RDC no 221/02. Piracicaba, SP, 2012

\begin{tabular}{|c|c|c|c|c|}
\hline \multirow{3}{*}{$\begin{array}{l}\text { Requisitos sanitários - promoção comercial nos } \\
\text { estabelecimentos }\end{array}$} & \multicolumn{4}{|c|}{ Frequência (\%) } \\
\hline & \multicolumn{2}{|c|}{ Drogarias n (\%) } & \multicolumn{2}{|c|}{ Supermercados n (\%) } \\
\hline & Rede & Individual & Rede & Individual \\
\hline $\begin{array}{l}\text { ^Existem exposições especiais na comercialização dos } \\
\text { produtos }\end{array}$ & $23(54,8)$ & $38(61,3)$ & $17(50,0)$ & $9(32,1)$ \\
\hline $\begin{array}{l}\text { • Existem ofertas (cupons ou preço menor) para comer- } \\
\text { cialização dos produtos }\end{array}$ & $13(31,0)$ & $31(50,0)$ & $15(44,1)$ & $7(25,0)$ \\
\hline $\begin{array}{l}\text { * Existem prêmios ou brindes para a comercialização } \\
\text { dos produtos }\end{array}$ & $13(31,0)$ & $31(50,0)$ & $15(44,1)$ & $7(25,0)$ \\
\hline $\begin{array}{l}\text { ^Existem apresentações especiais para a comercializa- } \\
\text { ção dos produtos }\end{array}$ & $17(40,5)$ & $32(52,0)$ & $12(35,3)$ & $8(28,5)$ \\
\hline$n$ & $42(100,0)$ & $62(100,0)$ & $34(100,0)$ & $28(100,0)$ \\
\hline
\end{tabular}

Fonte: Elaboração própria.

aproximadamente dois terços das drogarias e em metade dos supermercados, feita prioritariamente por meio de exposições especiais e, principalmente, nas redes e franquias. Os produtos estavam posicionados próximos às entradas ou caixas dos estabelecimentos, frequentemente associados a displays fornecidos pelos fabricantes.

A existência de ofertas e brindes representou estratégia auxiliar na promoção 
comercial nos estabelecimentos, com predomínio nas drogarias de propriedade individual. As apresentações especiais estão vinculadas especificamente a kits contendo várias mamadeiras em uma mesma embalagem.

Na tabela 3, são descritas as irregularidades presentes nas marcas de bicos infantis e mamadeiras (19) e chupetas (24) encontradas em Piracicaba na época da pesquisa.

Marcas tradicionais e comercializadas nacionalmente como Lillo ${ }^{\circledR}, \mathrm{Kuka}^{\circledR}$ e Neopan ${ }^{\circledR}$ monopolizam a presença nos pontos de venda, sendo lideradas pela marca Lolly ${ }^{\circledR}$. Juntas, alcançam patamares próximos a $44 \%$ dos bicos, $56 \%$ das mamadeiras e $46 \%$ das chupetas expostos à venda nos estabelecimentos participantes. Ainda com linha completa de produtos, foram encontradas três marcas importadas: Avent ${ }^{\circledR}$, MAM $^{\circledR}$ e $\mathrm{NUK}^{\circledR}$, comercializadas exclusivamente nas grandes redes de supermercados e drogarias.

Para as marcas Anplas ${ }^{\circledR}$, Baby Paco $^{\circledR}$,
Baby Pop ${ }^{\circledR}$, Ideatex Baby ${ }^{\circledR}$, Jolly $^{\circledR}$, Mimosa ${ }^{\circledR}$, Pituca $^{\circledR}$, Pupy $^{\circledR}$ e Primo ${ }^{\circledR}$, não foi encontrada linha completa de produtos (apenas bicos ou chupetas). Seus pontos de venda limitaram-se entre um e dois, principalmente drogarias pequenas (de propriedade individual), e sua atuação conjunta foi muito menos expressiva que a verificada nas marcas tradicionais. A marca Kitstar ${ }^{\circledR}$ teve comportamento similar (não possui linha completa de produtos), mas sendo avaliada somente quanto a mamadeiras e bicos.

As demais marcas comerciais encontradas - Baby Go ${ }^{\circledR}$, Cefisa $^{\circledR}, \mathrm{FLY}^{\circledR}, \mathrm{Mamy}^{\circledR}$, New Baby $^{\circledR}$, Nina Baby ${ }^{\circledR}$, Ninet ${ }^{\circledR}$, Pepeta ${ }^{\circledR}$ e Petita ${ }^{\circledR}$ constituem grupo muito heterogêneo. A linha de produtos fabricados, locais de venda onde foram encontrados e sua influência individual variaram bastante, o que pode indicar serem marcas ainda em busca de espaço em um mercado acirradamente competitivo.

Tabela 3. Irregularidades por marca comercial e conforme produto avaliado. Piracicaba, SP, 2012

\begin{tabular}{|c|c|c|c|c|}
\hline \multirow[b]{2}{*}{ Marca $^{\circledR}$} & \multirow[b]{2}{*}{ Requisito irregular } & \multicolumn{3}{|c|}{ Produtos } \\
\hline & & $\operatorname{Bico}(n=113)$ & $\begin{array}{r}\text { Mamadeira } \\
(n=121)\end{array}$ & $\begin{array}{l}\text { Chupeta } \\
(n=127)\end{array}$ \\
\hline Anplas & 5,19 & 1 & 0 & 1 \\
\hline Avent & $8,10,11,12,13,14,15,19$ & 1 & 1 & 1 \\
\hline Baby Go & $15,18,19$ & 2 & 5 & 3 \\
\hline Baby Paco & $7,16,18,19$ & 0 & 0 & 1 \\
\hline Baby Pop & $5,6,7,8,9,10,12,14,15,16$ & 0 & 0 & 1 \\
\hline Cefisa & $5,8,12,13,15,17,18,19$ & 9 & 3 & 2 \\
\hline Ideatex / Baby & 15,19 & 0 & 0 & 1 \\
\hline Fly & $15,18,19$ & 2 & 2 & 0 \\
\hline Jolly & $12,16,19$ & 1 & 0 & 0 \\
\hline Kuka & $7^{\star}, 15,18,19$ & 16 & 18 & 19 \\
\hline Lillo & $15,18,19$ & 22 & 28 & 21 \\
\hline Lolly & $5,6^{\star}, 8^{\star} 10^{\star}, 11^{\star}, 12^{\star}, 14^{\star}, 15,16,17^{\star}, 18,19$ & 25 & 26 & 31 \\
\hline Mam & $8,9,10,11,12,13,14,15,18,19$ & 2 & 4 & 3 \\
\hline Mamy & $5,15,18,19$ & 1 & 4 & 2 \\
\hline Mimosa & $15,17,18,19$ & 1 & 0 & 1 \\
\hline
\end{tabular}




\begin{tabular}{|c|c|c|c|c|}
\hline Neopan & $15,18,19$ & 6 & 10 & 6 \\
\hline New Baby & $5,7,11,12,13,14,15,16,17,18,19$ & 0 & 3 & 1 \\
\hline Nina Baby & $8,11,13,15,16,17,18,19$ & 1 & 1 & 1 \\
\hline Ninet & $15,18,19$ & 1 & 1 & 3 \\
\hline Nuby & $8,9,10,12,14,18,19$ & 0 & 0 & 1 \\
\hline Nuk & $15,18,19$ & 4 & 4 & 6 \\
\hline Pepeta & $5,6,7,8,10,11,12,13,14,15,16,17,18,19$ & 9 & 5 & 13 \\
\hline Petita & $5,7,15,17,18,19$ & 5 & 1 & 5 \\
\hline Pituca & 15,19 & 0 & 1 & 1 \\
\hline Pupy & $5,6,7,8,9,10,14,16,17$ & 0 & 0 & 1 \\
\hline Primo & $15,18,19$ & 2 & 0 & 2 \\
\hline Kitstar & $15,17,19$ & 2 & 1 & 0 \\
\hline Krolon & $5,6,7,8,10,11,12,13,14,15,16$ & 0 & 3 & 0 \\
\hline
\end{tabular}

Fonte: Elaboração própria.

*um único exemplar da marca ${ }^{\circledR}$ analisado apresentou irregularidades.

\section{Discussão}

O presente estudo investigou as irregularidades sanitárias na promoção comercial e nos rótulos de produtos para lactentes comercializados e um município de médio porte e suas possíveis implicações para a saúde materno-infantil.

Segundo Burlandy et al. (2016), o lucro é um fim intrínseco do setor privado, independentemente do porte das empresas, do tipo de propriedade ou do grau de formalização. Afirmam, ainda, que suas práticas comerciais se referem tanto às atividades 'fim' (promoção das vendas e consumo de produtos) quanto às questões políticas; por exemplo, o bloqueio de medidas governamentais potencialmente contrárias aos seus interesses corporativos.

Investigação realizada na região nordeste do Brasil sobre a prevalência do uso de bicos artificiais por lactentes $(n=1357)$ constatou que $60,7 \%$ delas utilizavam esse produto, e outras $40,9 \%$ utilizavam chupetas (NUNES ET AL., 2012). Ademais, os autores verificaram que havia um grande estímulo ao consumo desses produtos de puericultura na região, fato este que pode ter apresentado grande impacto na frequência da utilização da mamadeira nessa população (NUNES ET AL., 2012).

O impacto do uso desses produtos na saúde bucal das crianças ainda é controverso. Abreu et al. (2016) advertem sobre a pouca discussão existente na literatura, até o momento, enfocando as associações entre hábitos bucais e má-oclusão nas dentições mista e permanente. Em uma revisão sistemática recente envolvendo estudos epidemiológicos, os autores concluíram não ser possível evidenciar uma associação entre amamentação, uso da mamadeira e má-oclusão. Tal achado decorreu da insuficiência de estudos com elevada qualidade metodológica para testar essas hipóteses, ou seja, que apresentavam desenhos longitudinais e melhor controle do risco de viés e dos fatores de confusão.

Mioto et al. (2014) investigaram, por meio de um estudo longitudinal realizado em Vitoria (ES), e que envolveu uma amostra representativa de pré-escolares ( 3 a 5 anos) com dentição decídua completa, a possível 
associação entre variáveis sociodemográficas, desmame precoce e desenvolvimento e manutenção de hábitos bucais deletérios. As autoras observaram que a maioria das crianças (65\%) adquiriu o hábito de sucção de chupeta logo após o nascimento e que aproximadamente um terço delas manteve esse hábito por três anos ou mais. As meninas apresentaram maior risco tanto para a manutenção da sucção de chupetas $(\mathrm{OR}=1,274)$ quanto para o desmame precoce $(\mathrm{OR}=$ 3,874 ), independentemente da classe social.

Estudo epidemiológico com crianças na faixa etária dos 12 aos 36 meses de idade em João Pessoa (PB) constatou uma prevalência de 61,6\% para o hábito da sucção de chupeta (ALBUQUERQUE ET AL., 2010). Na amostra avaliada, o uso de chupeta prolongou-se até a idade de 25 a 36 meses, caracterizando-a como hábito prejudicial para definição do padrão mastigatório na dentição decídua.

Devido à controvérsia ainda existente quanto à associação entre a alimentação oferecida por meio de mamadeiras e cárie dentária, Ávila et al. (2015) realizaram uma metanálise de estudos transversais com o objetivo de revisar sistematicamente a evidência científica relacionada com a associação entre aleitamento materno versus uso de mamadeira e cárie dentária na infância. As autoras verificaram que a prevalência de cárie aos 5 anos ainda permanece elevada no Brasil (46,6\%), que o risco de aparecimento da doença foi maior para as crianças alimentadas com mamadeiras, comparativamente ao aleitamento materno exclusivo $(\mathrm{OR}=0,43)$; e que a evidência científica indicou que o aleitamento pode ser um fator de proteção contra a cárie dentária em crianças pequenas.

A partir dessas evidências, constata-se que a inclusão de advertências por frases específicas na rotulagem implementada com a NBCAL é um recurso fundamental para o controle na indução ao consumo decorrente da ampliação de pontos de venda, exposição e promoção comercial (MONTEIRO, 2006; BURLANDY ET AL., 2016).

Mecanismos regulatórios como esses são muito importantes, pois diversos estudos apontam o hábito de sucção de bicos artificiais, principalmente a chupeta, como fator de risco para o desmame precoce, bem como provocam problemas no desenvolvimento craniofacial e da dentição (más-oclusões). Esses fatores, entretanto, sofrem influência do contexto socioeconômico e familiar (SANTOS NETO ET AL., 2008; MIOTTO ET AL., 2014).

Assim como ocorreu na NBCAL, outros países regulamentaram a produção e venda de mamadeiras e chupetas para controle dos riscos e prevenção de acidentes por asfixia, estrangulamento ou engasgamento (CHILE, 2014; KEIM ET AL., 2012). Estudo realizado em serviços de emergências médicas constatou média de 2.270 acidentes/ano envolvendo crianças menores de 3 anos no período de 1991 a 2010. Episódios de asfixias ou ferimentos na região da boca aconteceram por quedas durante uso de mamadeiras $(65,8 \%)$ ou chupetas (19,9\%), levando ao recolhimento de 16 milhões de chupetas nesse período (KEIM ET AL., 2012).

No Brasil, levantamento realizado pelo Instituto Brasileiro de Defesa do Consumidor encontrou irregularidades nos produtos pesquisados em cinco estados brasileiros resultando em notificação de 35 fabricantes. Verificou-se que aproximadamente $10 \%$ das empresas cometem irregularidades na rotulagem de bicos, chupetas e mamadeiras, enquanto 63\% promovem seus produtos de forma irregular nos pontos de venda. Esse estudo também constatou um aumento expressivo no número de irregularidades encontradas no período entre 2007 e 2014 (IDEC, 2015).

Essa tendência também foi observada no presente estudo, em que ocorreram altas frequências de irregularidades nos mesmos produtos, comercializados em estabelecimentos do município em questão. Desse modo, a NBCAL se constitui em um importante instrumento regulatório para o comércio de bicos, mamadeiras e chupetas, reduzindo o número de produtos irregulares disponíveis 
no Brasil (MONTEIRO, 2006). Ademais, sua existência empodera tanto a sociedade em geral como agentes e órgãos públicos quanto aos padrões de clareza necessários nas informações envolvendo a promoção comercial e rotulagem disponibilizados por fabricantes e fornecedores (ANVISA, 2002A; IBFAN BRASIL, 2007; MARINS; JACOB, 2015).

No presente estudo, foi aplicado um instrumento prático que pode auxiliar os serviços públicos de vigilância sanitária ou futuras pesquisas sobre o tema. Esse formulário contemplou as dimensões previstas na legislação e permitiu caracterizar os estabelecimentos/produtos conforme a qualidade das informações contidas nos rótulos/embalagens, promoção comercial contidas em bicos, mamadeiras e chupetas.

Análises econômicas veiculadas no meio empresarial demonstraram o impacto dessa relação nas restrições ao marketing. Fabricantes como as multinacionais detentoras das marcas Lillo e NUK (francesa), MAM (austríaca) e a nacional Kuka/Neopan mudaram radicalmente suas estratégias comerciais. A fim de conseguir redução no preço ao consumidor, suas vendas passaram a priorizar grandes redes de supermercados (MARTINEZ, 2009; AB PLAST..., 2011).

A acirrada concorrência entre fabricantes no segmento de puericultura leve no mercado interno leva à escassez na divulgação de informações que poderiam auxiliar a análise do consumo. A pouca divulgação sobre volume de produção ainda está restrita às fontes alternativas esbarrando em uma 'confidencialidade' por parte dos fabricantes, até para acompanhamento econômico pelos órgãos oficiais (BRASIL, 2009).

Dados mensais de uma empresa nacional desse setor indicaram a produção de 1,5 milhão de mamadeiras e 3,2 milhões de chupetas (2005). Para o ano de 2009, a fabricante Lillo projetou seu crescimento de comercialização para patamares entre 15 e $20 \%$. Neste período - 2011 - o faturamento das empresas líderes foi estimado em $\mathrm{R} \$ 300$ milhões, representando cerca de $80 \%$ de seus lucros, além de variação média anual de $10 \%$ entre 2010 e 2012 (MARTINEZ, 2009; BRASIL, 2009; COLLET, 2009; AB PLAST..., 2011).

Observa-se neste estudo elevado número de fabricantes para bicos, mamadeiras e chupetas, além da forte presença de marcas importadas ocorrendo diversas irregulares na promoção comercial, por meio de promoções e oferta de brindes. Apesar do volume de produção dessas mercadorias não ser objeto de estudo, essa grande diversidade desperta atenção sobre possível existência de um mercado consumidor em expansão. Esse fato pode acirrar ainda mais a disputa por consumidores e preços menores, acarretando desrespeito a padrões éticos de marketing na rotulagem e comercialização dos produtos.

A qualidade da informação presente em um determinado produto e disponibilizada de forma clara tende a aumentar a sua credibilidade (MARINS; JACOB, 2015). A ausência, inadequação ou erro no fornecimento de informações dificultam a interpretação e assimilação de informações contidas nos rótulos, e a correta tomada de decisão pelo consumidor, podendo colocar em risco sua saúde (MARINS; JACOB, 2015).

As questões, no que tange à alimentação, não podem ser negligenciadas, principalmente quando se referem a grupos populacionais específicos que requerem uma atenção especial, como no caso de bebês e crianças (MARINS; JACOB, 2015). Estudos indicam que o grau de informação das mães e o prolongamento do período de aleitamento natural também estão diretamente relacionados com a menor incidência de más-oclusões durante a fase inicial de desenvolvimento da criança (SOUZA; VALLE; PACHECO, 2006).

Os resultados do presente estudo evidenciam a necessidade de maior conscientização e envolvimento de diferentes atores sociais na fiscalização e controle dos riscos à saúde proveniente das irregularidades sanitárias na promoção comercial e rótulos de 
produtos para lactentes e crianças na primeira infância. Apenas abordagens fiscalizatórias oficiais não contemplam tal proteção, visto que existe certa permissividade no relacionamento entre indústrias e algumas entidades de classe, além de um nível regular do conhecimento relativo à norma regulamentadora que trata da rotulagem e promoção comercial de bicos, chupetas e mamadeiras (MONTEIRO, 2006; SILVA ET AL., 2012).

A fim de facilitar esse processo, elaborou-se e testou-se um instrumento simplificado para monitoramento da NBCAL que favorece a fiscalização do cumprimento da norma, tanto pelo leigo, pesquisadores, órgãos de vigilância sanitária, bem como por outros serviços envolvidos nas ações de promoção da saúde, especialmente no SUS.

\section{Conclusões}

Foram encontradas irregularidades significativas na comercialização de bicos, mamadeiras e chupetas tanto em drogarias como em supermercados. As irregularidades e deficiências na clareza das informações nos rótulos predominaram em marcas pouco tradicionais e sem linha completa de produtos; enquanto marcas comerciais líderes concentraram suas irregularidades na apresentação de advertências obrigatórias: omissões sobre 'prejuízos à fala e à dentição pelo uso prolongado' e controle de estímulo subjetivo ao consumo. Aliado à existência comum de exposições especiais dos produtos nos pontos de venda, reforçam a demanda pela simplificação nos instrumentos para melhoria no monitoramento desses produtos.

\section{Colaboradores}

\begin{abstract}
Alexandre Gomes Lopes - contribuiu na concepção, interpretação dos dados e elaboração do rascunho. Antônio Carlos Pereira contribuiu na concepção e revisão crítica do conteúdo. Emílio Prado da Fonseca - contribuiu na interpretação dos dados e elaboração do rascunho. Fábio Luiz Mialhe - contribuiu na revisão crítica do conteúdo e aprovação da versão final do manuscrito.
\end{abstract}




\section{Referências}

\section{AB PLAST MANUFATURADOS PLÁSTICOS LTDA. Projeto Mamadeiras BORN: Plano de viabilidade eco- nômica. Joinvile: Brave, 2011. Disponível em: <http:// www.brave.art.br/abplast/files/assets/downloads/ publication.pdf>. Acesso em: 27 fev. 2016.}

ABREU, L. G. et al. Breastfeeding, bottle feeding and risk of malocclusion in mixed and permanent dentitions: a systematic review. Brazilian Oral Research, São Paulo, v. 30, n. 1, mar. 2016. Disponível em: <http://www.scielo.br/scielo.php?script=sci arttext\&pid=S1806-83242016000100401\&lng=en\&nrm =iso >. Acesso em: 27 abr. 2017.

AGÊNCIA NACIONAL DE VIGILÂNCIA SANITÁRIA (ANVISA). Advertências em mamadeiras e chupetas vão estimular amamentação. 2002a. Disponível em: <http:// www. anvisa.gov.br/divulga/noticias/2002/070802_4. htm>. Acesso em: 4 abr. 2015.

Resolução no 221 de 5 de agosto de 2002a.

Regulamento técnico sobre chupetas, bicos, mamadeiras e protetores de mamilo. Diário Oficial [da] União, Brasília, DF, 5 ago. 2002b. Seção I.

Resolução $\mathrm{n}^{0} 222$ de 5 de agosto de 2002. Regulamento técnico para promoção comercial dos alimentos para lactentes e crianças de primeira infância. Diário Oficial [da] União, Brasília, DF, 6 ago. 2002c. Seção I.

ALBUQUERQUE, S. S. L. et al. A influência do padrão de aleitamento no desenvolvimento de hábitos de sucção não nutritivos na primeira infância. Ciência $\mathcal{E}$ Saúde Coletiva, Rio de Janeiro, v. 15, n. 2, p. 371-378, mar. 2010

ÁVILA, W. M. et al. Breast and bottle feeding as risk factors for dental caries: a systematic review and meta-analysis. PLOS One, Clifford, v. 10, n. 11, nov. 2015. Disponível em: <http://journals.plos.org/plosone/ article?id=10.1371/journal.pone.0142922 $>$. Acesso em: 28 abr. 2017

BRASIL. Ministério da Fazenda. Secretaria de
Acompanhamento Econômico. Parecer n. 06489/2009/ RJ COGCE/SEAE/MF, de 03 de setembro de 2009. Parecer técnico referente a ato de concentração entre as empresas TOTAL S/A e Gerber Brasil Indústria e comércio de Produtos Infantis Ltda. set. 2009. Disponível em: <http://wwwl.seae.fazenda.gov.br/littera/pdf/ 08012 010154200848.pdf>. Acesso em: 30 jul. 2015.

BURLANDY, L. et al. Políticas de promoção da saúde e potenciais conflitos de interesses que envolvem o setor privado comercial. Ciência \& Saúde Coletiva, Rio de Janeiro, v. 21, n. 6, p. 1809-1818, jun. 2016.

CHILE. Ministerio de Economia, Fomento y Turismo. Servicio Nacional del Consumidor. Evaluación de requisitos mecánicos de las características funcionales de chupetes para bebés y niños pequeños. Santiago: Sernac, 2014. Disponível em: < http://www.sernac.cl/ wp-content/uploads/2014/05/Evaluaci\%C3\%B3nde-Requisitos-Mec\%C3\%Alnicos-de-lascaracter\%C3\%ADsticas-Funcionales-de-Chupetes. pdf>. Acesso em: 20 abr. 2015

COLLET, L. Grupo Total adquiri Lillo em 2009. Gazeta Mercantil, Rio de Janeiro, abr. 2009. Disponível em: $<$ http://www.crayvalley.com.br/noticias/default.php? $\mathrm{id}=146>$. Acesso em: 30 jul. 2015.

\section{FUNDAÇÃO SISTEMA ESTADUAL DE ANÁLISE} DE DADOS (SEADE). Estatísticas vitais e saúde. 2015. Disponível em: <http://www.imp.seade.gov.br/frontend/\#/perfil >. Acesso em: 5 maio 2013.

GIMENEZ, C. M. M. et al. Prevalência de más oclusões na primeira infância e sua relação com as formas de aleita mento e hábitos infantis. Revista Dental Press de Ortodontia e Ortopedia Facial, Maringá, v. 13, n. 2, p. 70-83, abr. 2008.

\section{INSTITUTO BRASILEIRO DE DEFESA} DO CONSUMIDOR (IDEC). Leis de proteção ao aleitamento materno são desrespeitadas no Brasil, indica monitoramento da Ibfan

Brasil e Idec. 2015. Disponível em: < http://www. idec. org.br /o-idec/sala-de-imprensa/release/ 
leis-de-proteco-ao-aleitamento-materno-so-desrespeitadas-no-brasil-indica-monitoramento-da-ibfan-brasil-e-idec >. Acesso em: 27 fev. 2016.

KEIM, S. A. et al. Injuries associated with bottles, pacifiers, and sippy cups in the unitedstates, 1991-2010. Pediatrics, Illinois, v. 129, n. 6, p. 1104-1110, jun. 2012.

MARINS, B. R.; JACOB, S. C. Avaliação do hábito de leitura e da compreensão da rotulagem por consumidores de Niterói, RJ. Vigilância Sanitária em Debate, Rio de Janeiro, v. 3, n. 3, p. 112-129, ago. 2015.

MARTINEZ, C. Lei impõe limites ao setor de chupetas e mamadeiras. Valor Econômico, São Paulo, dez. 2009. Disponível em: <http://www.aleitamento.com/ amamentacao /conteudo. asp? cod=874>. Acesso em: 17 maio 2015 .

MIOTTO, M. H. M. B. et al. Aleitamento materno como fator de proteção contra a instalação de hábitos bucais deletérios. Revista CEFAC, São Paulo, v. 16, n. 1, p. 244251, fev. 2014

MONTEIRO, R. Norma brasileira de comercialização de alimentos para lactentes e crianças de primeira infância: histórico, limitações e perspectivas. Revista Panamericana de Salud Publica, Washington, v. 19, n. 5, p. 354-362, maio 2006.

NUNES, A. C. L. et al. Prevalência do uso de bicos artificiais em menores de um ano. Revista Rene, Fortaleza, n. 13, v. 5, p. 1182-90, set./out. 2012.

PAULA, L. O.; CHAGAS, L. R.; RAMOS, C. V. Monitoramento da norma brasileira de comercialização de alimentos infantis. Nutrire: Sociedade Brasileira de Alimentação e Nutrição, São Paulo, v. 35, n. 3, p. 43-55, dez. 2010.
REDE INTERNACIONAL EM DEFESA DO DIREITO DE AMAMENTAR (IBFAN BRASIL). Manual do Curso de Capacitação em Monitoramento. Jundiaí: IBFAN, 2007. Disponível em: <http://www.ibfan.org.br/documentos/ibfan/doc-678.pdf >. Acesso em: 15 mar. 2013

SALIBA, N. A. et al. Freqüência e variáveis associadas ao aleitamento materno em crianças com até 12 meses de idade no município de Araçatuba, São Paulo, Brazil. Revista Brasileira de Saúde Materno Infantil, Recife, v. 8, n. 4, p. 481-490, dez. 2008.

SANTOS NETO, E. T. et al. use as a risk factor for reduction in breastfeeding duration: a systematic review. Revista Brasileira de Saúde Materno Infantil, Recife, v. 8, n. 4, p. 377-389, dez. 2008.

SILVA, L. R.; VIEIRA, E. M. Conhecimento dos farmacêuticos sobre legislação sanitária e regulamentação da profissão. Revista de Saúde Pública, São Paulo, v. 38, n. 3, p. 429-437, jun. 2004.

SOUZA, D. F. R. K.; VALLE, M. A. S.; PACHECO, M. C. T. Relação clínica entre hábitos de sucção, má oclusão, aleitamento e grau de informação prévia das mães. Revista Dental Press de Ortodontia e Ortopedia Facial, Maringá, v. 11, n. 6, p. 81-90, dez. 2006.

\section{WORLD HEALTH ORGANIZATION (WHO).}

Evidence on the long-term effects of breastfeeding: systematic review and meta-analyses. Geneva: WHO, 2007.

\footnotetext{
Recebido para publicação em dezembro de 2016

Versão final em maio de 2017

Conflito de interesses: inexistente

Suporte financeiro: não houve
} 